\title{
ZONEAMENTO DE RISCOS DE INCÊNDIOS FLORESTAIS PARA A FAZENDA EXPERIMENTAL DO CANGUIRI, PINHAIS (PR)
}

\author{
Luciene Ribeiro*, Letícia de Paulo Koproski**, Lorena Stolle***, Christel Lingnau****, \\ Ronaldo Viana Soares*****, Antonio Carlos Batista****** \\ *Bióloga, Doutoranda em Engenharia Florestal, UFPR - lucienefloresta@gmail.com \\ **Médica Veterinária, Doutoranda em Engenharia Florestal, UFPR - koproski@gmail.com \\ ***Enga. Florestal, Mestranda em Engenharia Florestal, UFPR - lorenasttole@yahoo.com.br \\ ****Eng ${ }^{\mathrm{a}}$. Florestal, Dr ${ }^{\mathrm{a}}$., Departamento de Ciências Florestais, UFPR - lingnau@ufpr.br \\ *****Eng. Florestal, Ph.D., Departamento de Ciências Florestais, UFPR - rvsoares@ufpr.br \\ ******Eng. Florestal, Dr., Departamento de Ciências Florestais, UFPR - batistaufpr@ufpr.br \\ Recebido para publicação: 02/10/2007 - Aceito para publicação: 06/12/2007
}

\begin{abstract}
Resumo
O presente trabalho teve como objetivo a elaboração de um mapa de zoneamento de riscos de incêndios florestais para a fazenda experimental do Canguiri, localizada no município de Pinhais (PR), pertencente à UFPR. Com o auxilio do SIG, foram produzidos mapas de riscos referentes à declividade, à exposição das encostas, à altimetria, à rede viária, à hidrografia e ao uso do solo. Esses parâmetros foram integrados por uma somatória em que todas as variáveis receberam o mesmo peso. A sobreposição dessas informações gerou o mapa de zoneamento de riscos de incêndios florestais, cujos resultados apontaram risco baixo para $12,7 \%$ da área, moderado para $52 \%$, alto para $29,9 \%$, muito alto para 5,8\%. Não foi observado risco extremo na área da fazenda. Esses percentuais foram considerados aceitáveis, uma vez que a ocupação do perímetro da fazenda é predominantemente agrossilvipastoril, com utilização do fogo como ferramenta de manejo.

Palavras-chave: Zoneamento de risco; fazenda Canguiri; incêndios florestais; SIG.
\end{abstract}

\begin{abstract}
Fire risk map for the Canguiri Experimental Farm, Pinhais (PR). The objective of this research was the elaboration of a fire risk map for the Canguiri Experimental Farm, located in Pinhais county, State of Parana, Brazil, owned by the Federal University of Parana. With the support of geoprocessing tools, individual maps for declivity, aspect, altimetry, roads, hydrography and land use were produced. These variables, with the same degree of importance, were integrated by addition. The individual maps overlapping generated the fire risk map, that presented the following results: low risk for $12.7 \%$ of the area, moderate risk for $52 \%$, high risk for $29.9 \%$, and very high risk for $5.8 \%$; no extreme risk was detected in the area. These percentages were considered acceptable, since land occupation in the experimental farm perimeter is mainly agriculture and pasture, where fire has been used as a managing tool.
\end{abstract}

Keywords: Fire risk map; Canguiri farm; forest fire; GIS.

\section{INTRODUÇÃO}

O fogo é o elemento mais comumente utilizado no manejo de ambientes agropastoris, por ser viável economicamente e já estar inserido na cultura agrícola de diversas civilizações. Sendo uma realidade indiscutível e que quando mal conduzida provoca desastres ecológicos e danos materiais imensuráveis, a melhor forma de atenuá-la é gerar um conhecimento do grau de risco específico para cada região.

Diversas medidas de prevenção e combate aos incêndios têm sido adotadas para minimizar os efeitos negativos do fogo. Os zoneamentos de risco de incêndios, ou mapas de risco, são instrumentos fundamentais no planejamento racional dos recursos destinados à prevenção e pré-supressão dos incêndios florestais. 
Segundo Oliveira (2002), os zoneamentos de risco de incêndios são elementos básicos para o planejamento da proteção de áreas florestais. Eles proporcionam uma visualização da distribuição espacial do risco em toda a área protegida e possibilitam uma adequação dos recursos e equipamentos destinados à prevenção e combate de acordo com o nível de perigo de cada região.

De acordo com Ferraz; Vettorazzi (1998), com as informações obtidas pelos mapas de risco várias medidas podem ser tomadas para se reduzir a ocorrência de incêndios, tais como maior vigilância nas áreas de risco, restrição de acesso a esses locais, construção de aceiros preventivos e reorganização das práticas de manejo, bem como auxílio ao combate, como, por exemplo, com a construção de estradas de acesso rápido aos locais de risco e alocação de recursos de combate em pontos estratégicos.

Uma zona de risco de incêndio é uma área delimitada em função do potencial de ocorrência e propagação do fogo, identificada pelas características ambientais comuns que se traduzem em um mesmo potencial de risco. As zonas de risco são delimitadas segundo a distribuição de pontos de ignição de incêndios (SHOW; CLARKE, 1953).

A análise criteriosa de cada variável associada ao risco de incêndios permite o estabelecimento de graus de risco de acordo com a sua influência sobre a ignição e a propagação do fogo. A definição dos níveis de risco para cada variável é a parte mais importante e de maior dificuldade na elaboração dos mapas. A etapa final do zoneamento é a superposição dos diversos mapas elaborados para a delimitação de áreas de acordo com o nível de risco em função da somatória ponderada dos riscos parciais de cada variável previamente analisada (BATISTA, 2000).

Diversos pesquisadores têm utilizado metodologias diversificadas no desenvolvimento de zoneamento de risco de incêndios florestais, que permitem associar os fatores ambientais de uma região com os incêndios florestais, possibilitando o mapeamento de risco potencial de incêndios em função da sensibilidade dos fatores analisados em relação ao fogo. O melhor modelo de ponderação é aquele definido de acordo com as condições de ocorrência dos incêndios locais e que considera a importância de cada variável em função da área de estudo (OLIVEIRA, 2002).

O sensoriamento remoto aliado ao SIG permite criar ferramentas de planejamento de áreas e utilizá-las como "automatizadoras" de execução cartográfica, colocando em prática o relevante potencial do sistema de informações geográficas no suporte do planejamento ambiental (ENCINAS, 2000). Sendo assim, o sistema de informações geográficas possibilita a criação de mapas de fragilidades ambientais, bem como de riscos de incêndios florestais.

O objetivo principal deste trabalho foi estabelecer o zoneamento de risco de incêndios florestais para a Fazenda Experimental do Canguiri, pela análise dos fatores físicos do local, associados às fontes de ignição e aos fatores de propagação dos incêndios.

\section{MATERIAL E MÉTODOS}

\section{Área de estudo}

A Fazenda Experimental do Canguiri, gerenciada pelo Setor de Ciências Agrárias da Universidade Federal do Paraná (UFPR), está localizada no município de Pinhais (PR), na região metropolitana do município de Curitiba, distante $18 \mathrm{~km}$ ao norte dessa capital. As coordenadas centrais aproximadas no Sistema de Projeção Cartográfica UTM, Datum SAD-69 Zona 22S, são: $686.000 \mathrm{~m} \mathrm{e}$ 7.190.000 m (Figura 1).

Segundo o sistema de classificação climática de Köppen, a região é caracterizada pelo clima temperado (ou subtropical) úmido mesotérmico $(\mathrm{Cfb})$, sem estação seca, com verões frescos e invernos com geadas freqüentes e ocasionais precipitações de neve. Segundo o sistema de Holdridge, o clima local é Bosque Úmido Subtropical Montano Baixo.

Os ventos predominantes são da direção Leste, com velocidade média anual de $2,1 \mathrm{~m} \cdot \mathrm{s}^{-1}$. A temperatura média anual é de aproximadamente $16,5^{\circ} \mathrm{C}$, sendo fevereiro (média de $20,3{ }^{\circ} \mathrm{C}$ ) o mês mais quente e julho (média de $12,7^{\circ} \mathrm{C}$ ) o mais frio.

A precipitação média anual (período de 1970 a 1997) é de 1415 mm (SIMEPAR). São encontradas as unidades fitogeográficas Floresta Ombrófila Mista e Estepe, de acordo com os critérios estabelecidos pelo Sistema de Classificação da Vegetação Brasileira proposto pelo IBGE (1992).

O uso do solo está disposto de acordo com a figura 2: a agricultura ocupa uma área de 228,58 ha $(53,3 \%)$, o campo sujo 47,9 ha $(11,2 \%)$, a floresta nativa 100,6 ha $(23,5 \%)$ e o reflorestamento de Pinus 
28,5 ha (6,6\%). As estradas ocupam 10,7 ha (2,5\%) e a área de circulação (habitações e outras construções) 7,5 ha (1,7\%). A área úmida, que contém o lago, ocupa 4,5 ha (1,0\%), e os banhados 0,4 ha $(0,09 \%)$. O total da área é de 428,68 ha.
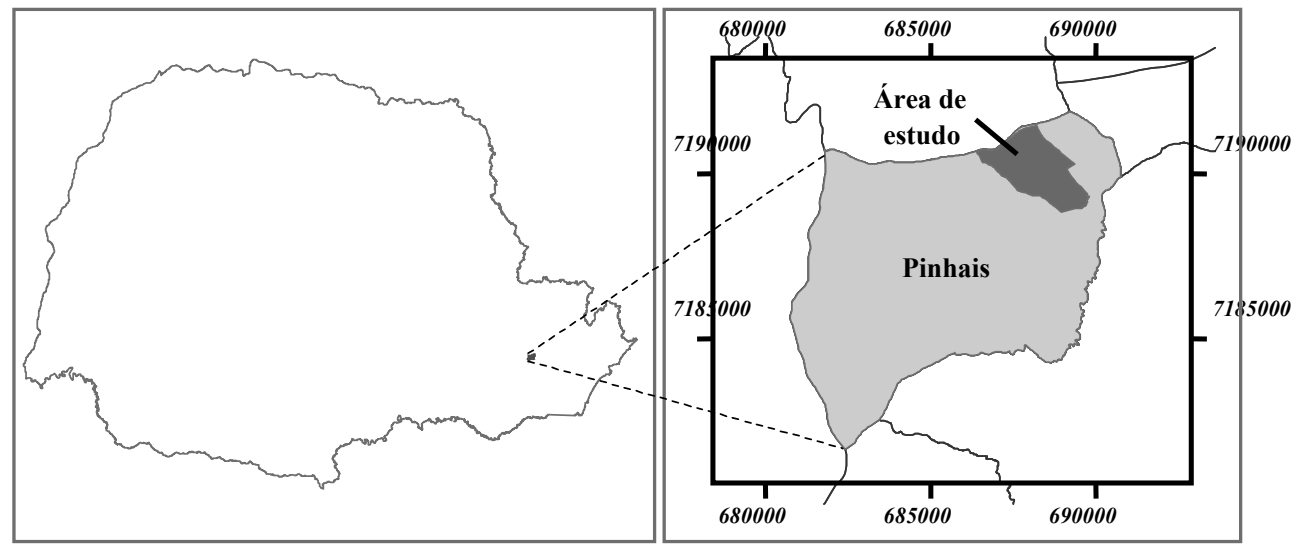

Sistema de Projeção Cartográfica UTM

Datum SAD-69 Fuso 22S

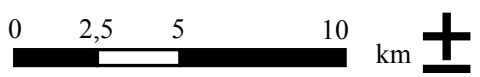

Figura 1. Localização da Fazenda Experimental do Canguiri.

Figure 1. Localization of the Canguiri Experimental Farm.

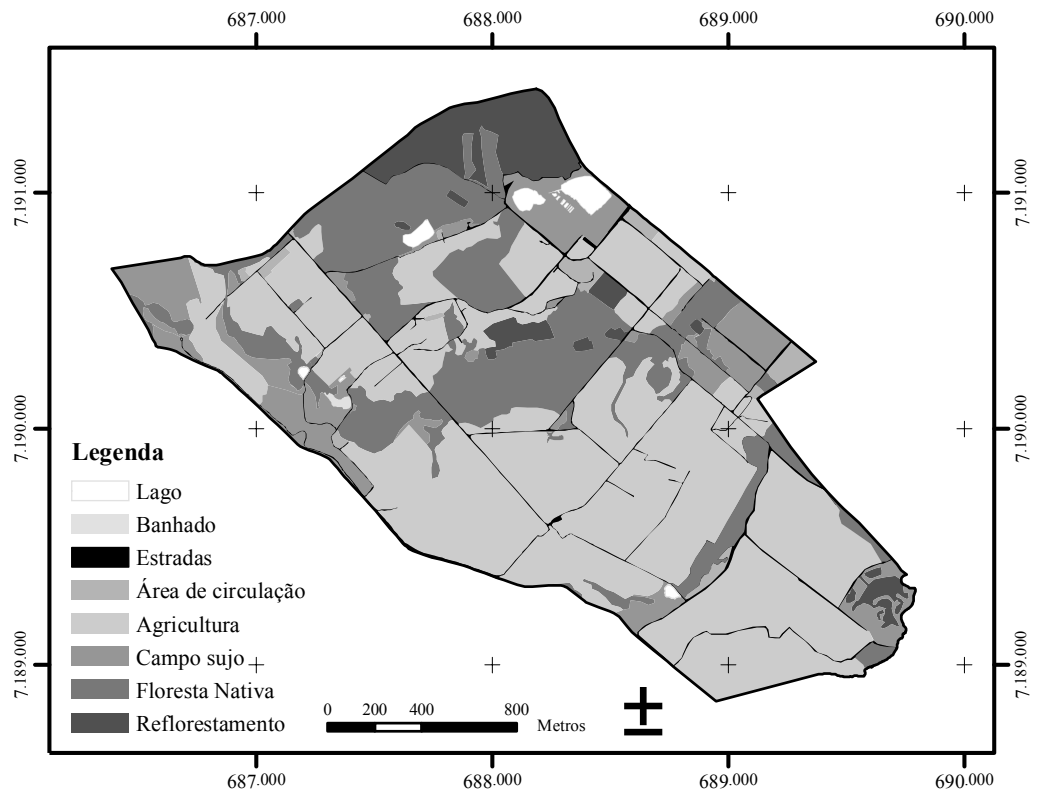

Figura 2. Mapa de uso atual do solo da Fazenda Experimental do Canguiri.

Figure 2. Land use map of the Canguiri Experimental Farm.

\section{Informações cartográficas}

As curvas de nível com eqüidistância de 10 metros foram obtidas a partir do arquivo digital elaborado pela SUDERHSA no ano de 2000 (na escala 1:20.000) da Coordenação da Região Metropolitana de Curitiba (COMEC). Foi gerado o modelo digital de superfície TIN (Triangulated Irregular Network). 
As demais informações, tais como uso do solo, hidrografia e rede viária, foram obtidas através da digitalização de ortofoto, ano de 2004, na escala de 1:10.000, disponível no laboratório de geoprocessamento do curso de Engenharia Florestal da UFPR.

\section{Métodos}

Os fatores ambientais são considerados de acordo com as condições de riscos locais e com o critério que mais se ajusta a cada situação de risco. São exemplos de análises: tipo e densidade de vegetação, declividade do terreno, exposição das encostas, elevação do terreno, benfeitorias, trafegabilidade da rede viária, influência da vizinhança e fatores climáticos, entre outros.

$\mathrm{O}$ estudo em questão baseou-se em parâmetros já trabalhados para o estado do Paraná por Batista, Oliveira e Soares (2002), contemplando as variáveis referentes à declividade do terreno, orientação das encostas, altitude, sistema viário, hidrografia e uso do solo. Posteriormente, houve uma sobreposição de todos as variáveis para geração do mapa de zoneamento do risco de incêndios florestais.

\section{Mapas de risco}

\section{Declividade}

Os valores de declividade foram distribuídos em cinco classes, que correspondem aos riscos 'Baixo', 'Moderado', ‘Alto', 'Muito alto' e ‘Extremo'. Para cada classe, atribuiu-se um peso indicando o nível de risco, o qual foi a base para a operação algébrica posterior. A tabela 1 relaciona o grau de inclinação do terreno em função da sua influência na taxa de propagação do fogo.

Tabela 1. Classificação segundo a declividade do terreno.

Table 1. Slope ranking.

\begin{tabular}{lcc}
\hline Declividade (\%) & Risco & Pesos \\
\hline Até 15 & Baixo & 1 \\
$16-25$ & Moderado & 2 \\
$26-35$ & Alto & 3 \\
$36-45$ & Muito alto & 4 \\
$\geq 46$ & Extremo & 5 \\
\hline
\end{tabular}

Orientação das encostas

A orientação das encostas, devido às condições de iluminação pelo sol, influencia na umidade e tipo do material combustível. As condições de risco em função da orientação das encostas para o hemisfério Sul foram distribuídas em cinco classes, apresentadas na tabela 2. Para cada classe atribuiu-se um peso referente ao nível de risco.

Tabela 2. Classificação da orientação das encostas.

Table 2. Aspect orientation ranking.

\begin{tabular}{lcc}
\hline Exposição & Riscos & Pesos \\
\hline SE / S SW & Baixo & 1 \\
E & Moderado & 2 \\
NE & Alto & 3 \\
NW / W & Muito alto & 4 \\
N & Extremo & 5 \\
\hline
\end{tabular}

\section{Altimetria}

A variação da altitude representa uma variável ambiental que influencia o risco de incêndio devido a sua relação com a umidade relativa do ar. Isso se deve ao fato de que, com o aumento da altitude, observa-se um decréscimo da temperatura e, conseqüentemente, um valor elevado de umidade relativa (SALAS e CHUVIECO, 1994). Dessa forma, o mapa de altitude representa indiretamente a umidade do material combustível e conseqüentemente a redução do risco de incêndio. Os valores foram distribuídos em cinco classes, apresentadas na tabela 3. 
Tabela 3. Classificação da altimetria.

Table 3. Altimetry ranking.

\begin{tabular}{lcc}
\hline Classe altimétrica & Risco & Pesos \\
\hline Até $600 \mathrm{~m}$ & Extremo & 5 \\
$600-900 \mathrm{~m}$ & Muito alto & 4 \\
$900-1200 \mathrm{~m}$ & Alto & 3 \\
$1200-1500 \mathrm{~m}$ & Moderado & 2 \\
Acima de $1500 \mathrm{~m}$ & Baixo & 1 \\
\hline
\end{tabular}

\section{Distribuição do sistema viário}

As estradas ou mesmo trilhas são os elos que permitem a exploração mais eficiente de uma região, logo, podem também ser fator desencadeante de risco proeminente de incêndios florestais e devem ser consideradas quando se realiza uma análise de zoneamento de riscos de fogo.

O raio de influência definido foi de 50 metros para as estradas vicinais existentes na área de estudo. Esse valor foi considerado devido às estradas internas da fazenda possuírem tráfego pouco intenso, diferentemente de auto-estradas, onde o raio de risco em média é de 100 metros, de acordo com Chou et al. (1990). As áreas delimitadas pelos raios de influência foram consideradas sob risco pelo potencial de ignição de incêndios próximos à estrada.

Tabela 4. Classificação da distribuição do sistema viário.

Table 4. Road system ranking.

\begin{tabular}{lcc}
\hline Classes & Risco & Pesos \\
\hline Sob influência & Sim & 1 \\
Sem influência & Não & 0 \\
\hline
\end{tabular}

Hidrografia

A proximidade com corpos de água pode ser positiva ou negativa. São consideradas positivas por servirem como barreira à propagação do fogo, e negativas quando recebem visitação humana, seja para recreação, pesca ou realização de rituais religiosos (geralmente, a causa de muitos incêndios florestais iniciados em margens de rios é decorrente desse tipo de visitante). $\mathrm{O}$ raio de influência definido foi de 50 metros para todos os corpos de água presentes na área. As áreas delimitadas pelos raios de influência foram consideradas sem riscos, devido à maior proximidade aos corpos de água, enquanto as demais foram consideradas sob risco.

Tabela 5. Classificação segundo a influência da hidrografia.

Table 5. Hydrographic influence ranking.

\begin{tabular}{lcc}
\hline Classes & Risco & Pesos \\
\hline Sob influência & Sim & 1 \\
Sem influência & Não & 0 \\
\hline
\end{tabular}

\section{Uso do solo}

O conhecimento sobre o uso do solo é fundamental para que se compreenda o nível de riscos aos quais os sistemas estão sujeitos, bem como a forma mais adequada de manejo. Os sistemas agrossilvipastoris são os mais propensos ao risco de incêndios florestais, devido ao tipo de manejo, utilizando-se o fogo, em razão de seu baixo custo e outros benefícios.

Tabela 6. Classificação de risco segundo o uso do solo.

Table 6. Ranking of forest fire risk according land use.

\begin{tabular}{lcc}
\hline Classes de riscos & Uso do solo & Pesos \\
\hline Baixo & Lago/banhado/áreas de circulação & 1 \\
Moderado & Floresta & 2 \\
Alto & Estradas & 3 \\
Muito alto & Reflorestamento & 4 \\
Extremo & Campo sujo/agricultura & 5 \\
\hline
\end{tabular}




\section{Elaboração do mapa de risco de incêndios}

Os mapas de declividade, orientação das encostas, altimetria, sistema viário, hidrografia e uso do solo foram integrados por uma somatória em que todas as variáveis receberam o mesmo peso. O modelo de integração dos dados é expresso pela equação 1 (BATISTA, OLIVEIRA e SOARES, 2002).

Em que:

$$
\mathrm{RISCO}=\mathrm{DV}+\mathrm{OE}+\mathrm{AL}+\mathrm{SV}+\mathrm{HD}+\mathrm{US}
$$

DV: coeficiente de risco segundo a declividade;

OE: coeficiente de risco segundo a orientação das encostas;

AL: coeficiente de risco segundo a altimetria;

$\mathrm{SV}$ : coeficiente de risco segundo o sistema viário;

HD: coeficiente de risco segundo a hidrografia;

US: coeficiente de risco segundo o uso do solo.

O mapa de risco resultante traduz a influência das seis variáveis analisadas sobre o risco e a propagação dos incêndios na Fazenda Canguiri. As classes de risco foram consideradas de acordo com as potencialidades de ignição e se encontram relacionadas na tabela 7.

Tabela 7. Classes de risco de incêndios florestais de acordo com o potencial de ignição.

Table 7. Ranking of forest fire risk according to the ignition potential.

\begin{tabular}{lc}
\hline Classes de pesos & Classes de riscos \\
\hline $4-8$ & Baixo \\
$9-12$ & Moderado \\
$13-16$ & Alto \\
$17-20$ & Muito alto \\
$21-22$ & Extremo \\
\hline
\end{tabular}

\section{RESULTADOS E DISCUSSÃO}

\section{Declividade}

O relevo exerce grande influência sobre o clima e, em menor escala, sobre a vegetação e conseqüentemente sobre o material combustível das diversas regiões terrestres, criando uma tendência do fogo de se propagar mais rapidamente nos aclives e mais lentamente nos declives. Um incêndio, quando se propaga em um aclive acentuado, se assemelha a um incêndio se propagando no plano, sob efeito de forte vento.

De acordo com Goldammer (1982), a topografia apresenta forte influência no comportamento do fogo, atuando das seguintes maneiras:

- Aumenta a intensidade do fogo nas áreas de aclive devido ao material combustível, acima da frente do fogo, estar mais próximo das chamas do que em terrenos planos (aquecimento do material combustível).

- Nas encostas norte e noroeste existem fluxos de ar quente devido à radiação solar ao meiodia e durante o período da tarde. As correntes de ar movimentam-se para cima das encostas, aumentado grandemente a propagação do fogo.

- Vales estreitos e precipícios funcionam como "chaminés", cuja corrente de ar adaptam-se à topografia do terreno.

- Estrutura e situação do solo também influenciam na ação do fogo, ou seja, solos arenosos e solos das encostas norte têm menor umidade e, portanto, fornecem menor umidade ao ambiente.

Como se verifica na figura 3, a maior porção $(99,3 \%)$ representa 425,7 ha da região de estudos e possui menos de $15 \%$ de declividade, apresentando 'Baixo' risco em relação ao fogo. Uma pequena porção na região central e nordeste $(0,68 \%)$, com 2,9 ha, com declividade de 16 a $25 \%$, representa risco 'Moderado', e uma porção ínfima (0,04\%), representando 0,2 ha, ao sudeste, com declividade de 26 a $35 \%$, apresenta um risco 'Alto' de fogo, significando que, quanto à declividade, os riscos são 'Baixos', não expondo a área ao risco proeminente de fogo. 


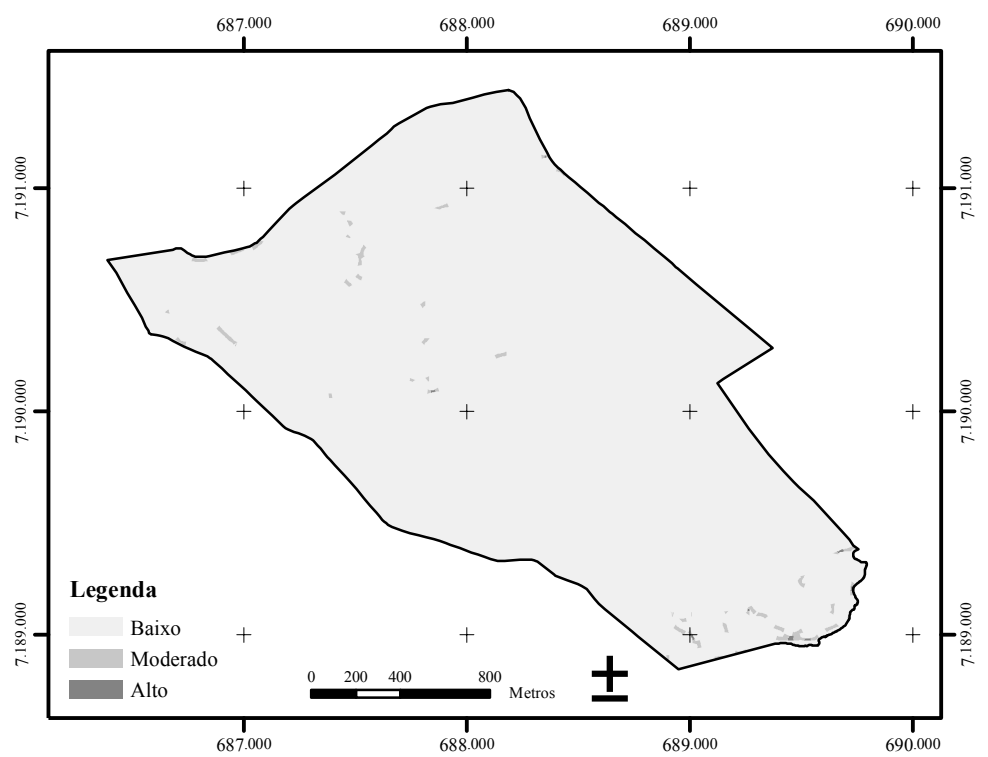

Figura 3. Mapa de declividade da Fazenda Canguiri.

Figure 3. Declivity map of the Canguiri Experimental Farm.

\section{Orientação das encostas}

A exposição de um terreno é fator essencial na probabilidade de ocorrência e propagação de um incêndio. No hemisfério Sul, os raios solares incidem mais diretamente sobre faces voltadas para o norte, transmitindo maior quantidade de calor para essa exposição do que para as outras. A face oeste é a segunda a receber maior quantidade de energia, seguida da face leste. A face sul é a que menos recebe radiação (Figura 4).

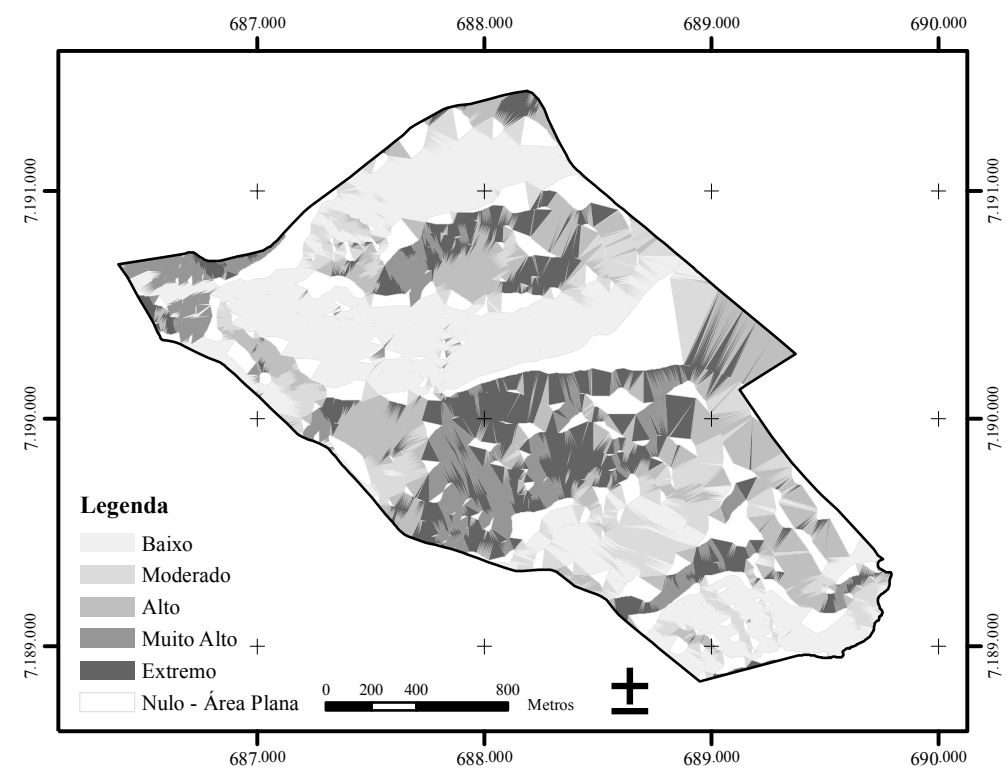

Figura 4. Mapa de risco segundo a orientação das encostas para a Fazenda Experimental do Canguiri, Pinhais (PR).

Figure 4. Forest fire risk according to hillshade orientation map of the Canguiri Experimental farm. 
Mesmo no verão, em latitude maior que $23^{\circ} 27^{\prime}$, a face sul nunca recebe insolação direta. Isso se deve à inclinação da Terra em relação ao Sol. Dessa forma, o efeito da exposição aumenta de acordo com o aumento da latitude. As temperaturas mais elevadas no norte são justificadas pela maior exposição de radiação e pela menor umidade relativa, sendo que o material combustível seca mais rapidamente e, por essa razão, o risco de ocorrência e propagação de incêndios florestais nessa exposição é maior que nas demais.

\begin{abstract}
Altimetria
De acordo com Batista, Oliveira e Soares (2002), a elevação do terreno em relação ao nível do mar é muito importante, pois afeta as condições climáticas locais e conseqüentemente atua nas características de umidade do material combustível. Baixas elevações têm a tendência de apresentar estações de risco de incêndios mais longas que altas elevações. Topos de montanha e fundos de vale apresentam diferentes condições de queima durante o dia. Devido às correntes de vento e às condições de temperatura e umidade predominantes nos dois locais, os fundos de vale apresentam maior potencial de propagação de fogo durante o dia, com a situação se invertendo durante a noite.

Conforme ilustra a figura 5, a altimetria de 600 a 900 m representa um risco 'muito alto' (12,4\%) em 53,1 ha, e 'Alto' (87,6\%) em 375,7 ha, que se referem à altimetria de 900 a 1.200 m.
\end{abstract}

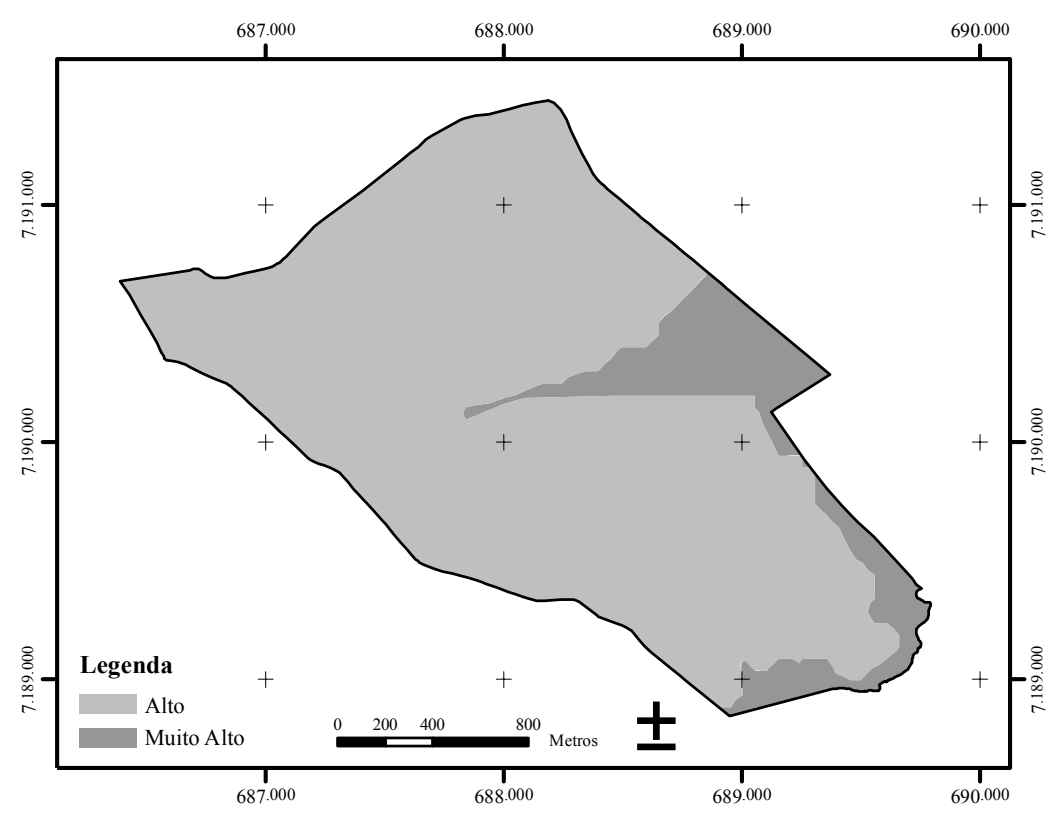

Figura 5. Mapa de risco segundo a altimetria para a Fazenda Experimental do Canguiri, Pinhais (PR).

Figure 5. Forest fire risk according to altimetry map of the Canguiri Experimental Farm.

\title{
Distribuição do sistema viário
}

No setor florestal, a rede viária é a principal base de todas as atividades, sobretudo no transporte de matéria-prima. No entanto, essas estradas têm sido uma das principais causas da erosão e do assoreamento dos cursos d'água, principalmente em florestas plantadas. Além disso, o acesso de pessoas e veículos causa risco de incêndio por vários fatores, como incêndios criminosos, prática de cultos religiosos, incêndios causados por cigarros e práticas de pequenas fogueiras, entre outras ocorrências (FERRAZ e VETTORAZZI, 1998).

A área de estudos é cortada por várias estradas internas estreitas e com trânsito reduzido de veículos e pessoas. Mesmo as estradas sendo estreitas e com baixo trânsito de veículos e pessoas, há algum impacto que, por menor que seja, não deve ser ignorado em um trabalho de zoneamento do fogo.

Para tanto, no presente trabalho, o raio de influência foi de $100 \mathrm{~m}$, sendo $50 \mathrm{~m}$ de cada lado da estrada, representando 52,7\% da área total da Fazenda Canguiri (Figura 6). Esse valor pode e deve ser ajustado de acordo com a largura e uso das estradas e trilhas presentes em uma dada região. 


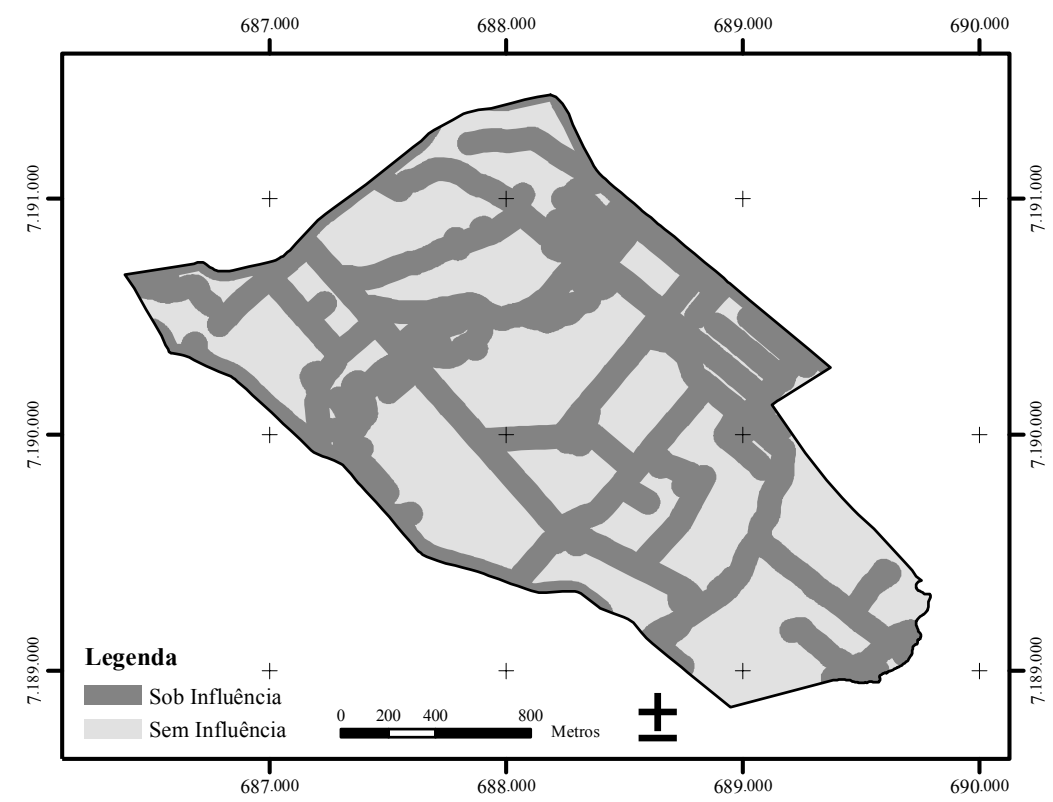

Figura 6. Influência das estradas sobre o risco de incêndios florestais na Fazenda Experimental do Canguiri.

Figure 6. Roads influence on fire risk in the Canguiri Experimental Farm.

\section{Hidrografia}

A rede hídrica foi considerada com influência no sentido de fornecer apoio para o caso de um incêndio na região da fazenda, sendo considerado apenas com influência positiva em um processo de incêndio florestal. No entanto, as informações sobre o impacto humano para o uso de recreação não foram contempladas neste trabalho. A área sob influência representa 7,5\% (32,3 ha) e 92,5\% (396,5 ha) para a área sem influência (Figura 7).

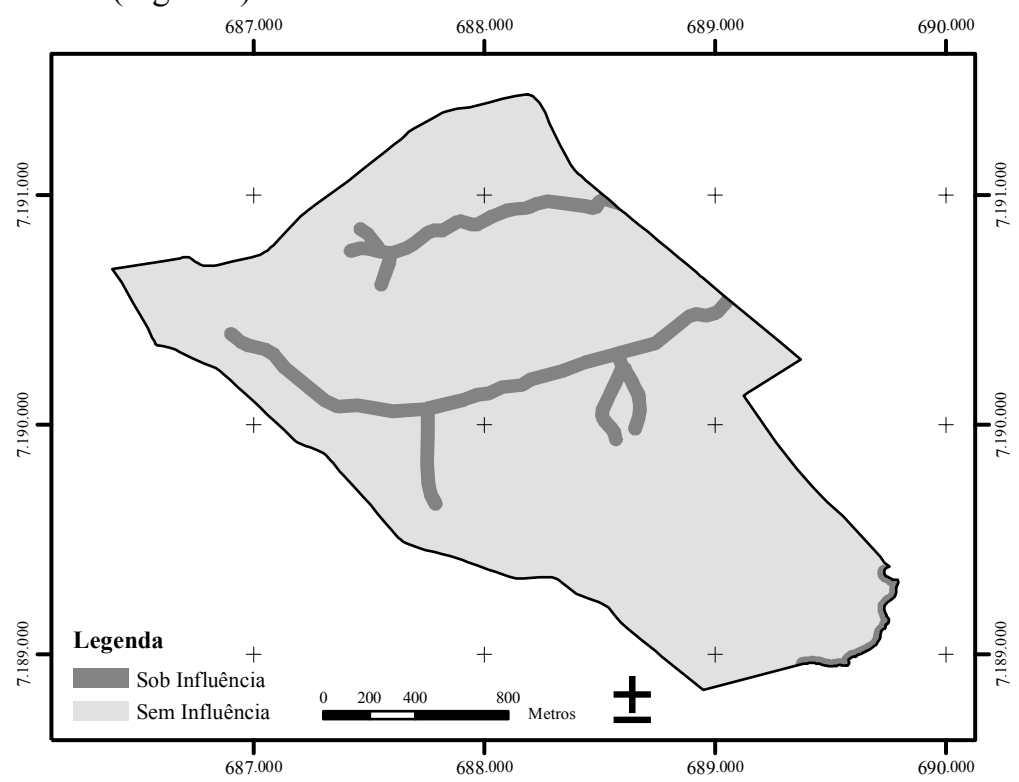

Figura 7. Influência da hidrografia sobre os riscos de incêndios florestais na Fazenda Experimental do Canguiri.

Figure 7. Hydrographic influence on fire risk in the Canguiri Experimental Farm. 


\section{Risco de fogo quanto ao uso do solo}

Os riscos quanto ao uso do solo podem ser observados na Figura 8: representam risco 'Extremo' $64,5 \%$ (ou 276,5 ha), referentes ao campo sujo e à agricultura, pois o manejo está baseado no uso do fogo e o risco em períodos de longa estiagem é proeminente, podendo o fogo sair do controle e atingir a região de reflorestamento e a floresta nativa. O risco 'Muito alto' se refere às áreas de reflorestamento de pinus, sendo que a susceptibilidade ao fogo é devida à grande quantidade de acículas que são depositadas sobre o solo. As florestas de pinus nos primeiros 12-18 anos podem atingir de 7 a 10 toneladas por hectare e por acúmulo de pequenos galhos, ambos de pequena espessura (menor que $2 \mathrm{~cm}$ ), e tem a propriedade de secagem mais rápida.

No remanescente de floresta nativa, o grau de risco é 'Moderado', representando 23,5\% (100,6 ha). A área é menos susceptível ao fogo do que o reflorestamento, devido às propriedades físicas e químicas das espécies presentes, havendo maior umidade no folhedo e nos galhos, porque ambos possuem espessura maior do que os restos orgânicos de um plantio de pinus, devido às características ecológicas das espécies e do microclima local. O risco 'Alto' obteve a proporção de 2,5\% de área (10,7 ha) e se refere às estradas, pois é nessa porção do terreno que ocorre maior trânsito de pessoas e veículos que, por um acidente qualquer (bitucas de cigarro, fósforos acesos, etc.), podem começar um incêndio.

O risco 'Baixo' se refere ao banhado, ao lago e a áreas de circulação (edificações), representando $2,9 \%$ do terreno (12,4 ha). Nessa porção especificamente, um incêndio florestal não vai acontecer, pois não há vegetação para ser queimada. O que acontece é que ela pode ser uma ameaça inicial ao fator de ignição, uma vez que é de uso antrópico constante.

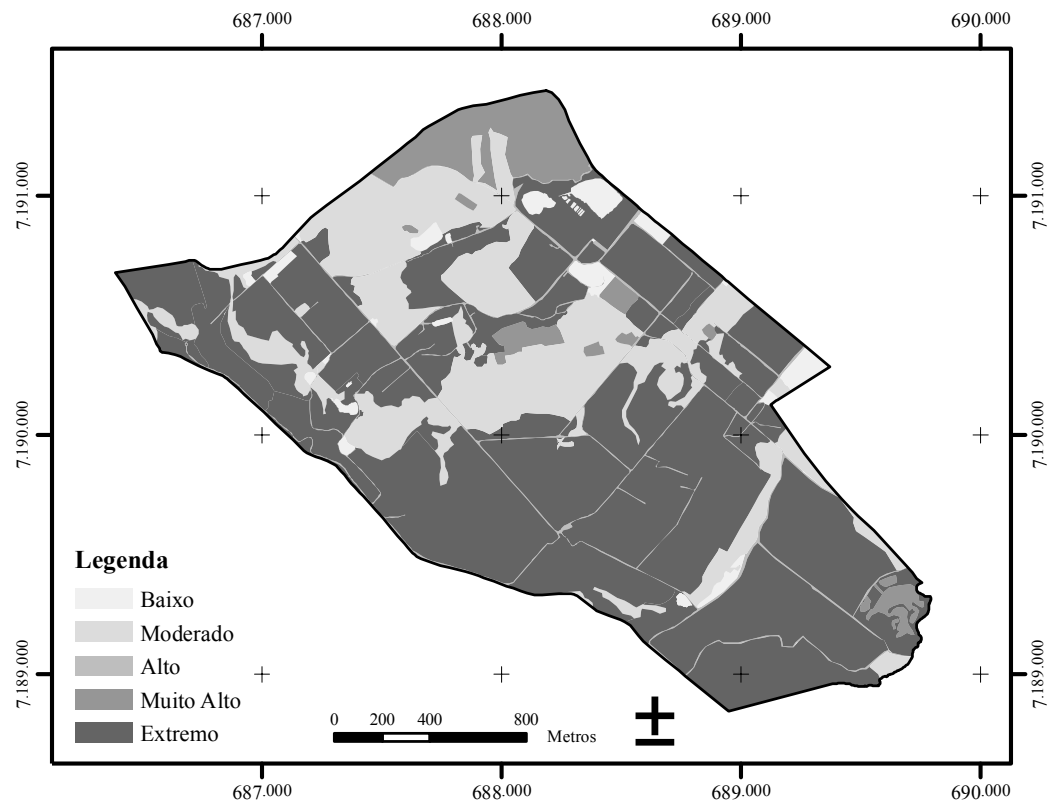

Figura 8. Influência do uso do solo sobre os riscos de incêndios florestais na Fazenda Experimental do Canguiri.

Figure 8. Land use influence on fire risk in the Canguiri Experimental Farm.

\section{Zoneamento de riscos de incêndios florestais}

O termo "incêndio florestal" é utilizado para definir um fogo que se propaga livremente, queimando todo o material vegetal existente em um sistema, seja ele com floresta ou não. Devido a isso, é que o mapeamento de riscos de incêndios florestais obtidos neste zoneamento implica risco de ocorrência de fogo mesmo em uma área de pastagem ou campo.

No cenário geral do zoneamento (Figura 9), o risco de fogo com maior área é 'Moderado', com $56,6 \%$, no total de 242,8 hectares. Para o risco 'Baixo', $19,4 \%$ da área (83,0 ha). Quanto ao risco 'Alto', que representou a segunda maior porção da área $(24,0 \%)$, ou seja, 103,0 hectares, pode ser considerado 
normal ou aceitável, pois todas as áreas de atividades agropastoris possuem certo risco em maior ou menor escala, mesmo em terreno plano, devido às formas de manejo aplicadas, tendo como base o fogo, atividade esta muito difundida em todas as regiões e por diferentes populações, uma vez que o fogo é a maneira mais fácil e barata de se renovar a pastagem e cultivar o solo agricultável. De acordo com as variáveis consideradas neste estudo, o risco 'Extremo' não está presente nessa área.

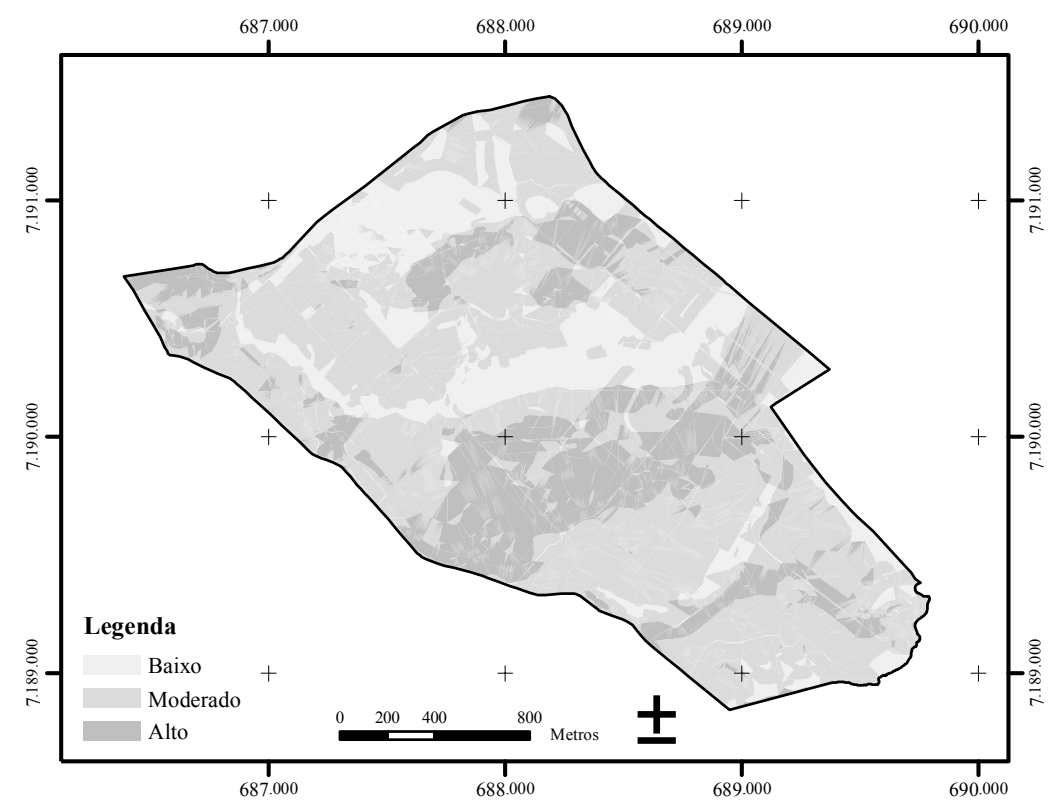

Figura 9. Zoneamento de riscos de incêndio florestal para a Fazenda Experimental do Canguiri. Figure 9. Fire risk map for the Canguiri Experimental Farm.

\section{CONCLUSÕES E RECOMENDAÇÕES}

- No âmbito do zoneamento de riscos de incêndios florestais, a Fazenda Experimental do Canguiri não possui risco 'Extremo'.

- O maior percentual de riscos se refere ao 'Moderado', representando 56,6\% da área.

- O risco ‘Alto’ é o segundo maior nível de risco, com $24,0 \%$.

- As áreas mais propensas ao fogo são as ocupadas por campos e pelo reflorestamento de pinus.

- A elaboração de mapas de risco de incêndios florestais pode ser utilizada para áreas privadas, unidades de conservação e até mesmo em nível municipal, considerando para isso as variáveis locais que influenciam no comportamento do fogo.

- Investir em uma política informativa é a forma mais econômica de se evitarem prejuízos maiores com o fogo originado por ação antrópica.

- Implantar cortinas de segurança (espécies não-inflamáveis que oferecem maior resistência à propagação do fogo). Exemplo: aveia e eucalipto, como segurança para Pinus e Araucária, são ações simples e que podem dar bons resultados para se minimizar a entrada do fogo em uma floresta plantada, como a existente na Fazenda Experimental do Canguiri.

\section{REFERÊNCIAS}

BATISTA, A. C. Mapas de risco: uma alternativa para o planejamento de controle de incêndios florestais. Revista Floresta, Curitiba, v. 30, n. 1, 2, 45-54, jun/dez. 2000. 
CHOU, Y. et al. 1 Spatial autocorrelation of wildfire distribution in the Idyllwild Quadrangle, San Jacinto Motains, California, USA. Environmental Management, New York, v. 17, n. 1, p.129-140, 1990.

CHUVIECO, E.; CONGALTON, R. G.. Aplication of remote sensing and geographic information systems to forest fire hazard mapping. Remote Sensoring of Enviromment, New York, v. 29. p. 147$159,1989$.

ENCINAS, J. I. Aplicação do sensoriamento remoto para caracterização ambiental de 80.000 ha, as margens do rio Paraguai. Brasília: UNB. Departamento de Engenharia Florestal, 2000.

GOLDAMMER, J. G. Incêndios florestais: prevenção, controle e uso do fogo. Irati: S.A.C.T., 1982. 93 p.

INSTITUTO BRASILEIRO DE GEOGRAFIA E ESTATÍSTICA (IBGE). Manual técnico da vegetação brasileira. Rio de Janeiro, 1992. 92 p. (Série: Manuais Técnicos em Geociências, n.1).

LOS INCÊNDIOS forestales en Iberoamerica. In: SEMINÁRIO IBEROAMERICANO SOBRE NUEVAS TECNOLOGIAS Y GESTION EN CATASTROFES, 1., 1997, Madrid. [Annales...]. Madrid: [s.n.], 1997. 87 p. (Seccion técnica incêndios forestales).

OLIVEIRA, D. S.; BATISTA, A. C.; MILANO, M. S. Fogo em Unidades de Conservação. In: CONGRESSO BRASILEIRO DE UNIDADES DE CONSERVAÇÃO, 2., 2000, Campo Grande. Anais do... Campo Grande: Rede Nacional Pró Unidades de Conservação, 2000. p. 200-207.

OLIVEIRA, D. S. Zoneamento de risco de incêndios florestais no norte de Santa Catarina. Curitiba. 112 f. Dissertação (Mestrado em Engenharia Florestal) - Setor de Ciências Agrárias, Universidade Federal do Paraná, Curitiba, 2002.

SOARES, R. V.; BATISTA, A. C. Curso de especialização por tutoria à distância controle de incêndios florestais: o problema do fogo na floresta e meteorologia aplicada aos incêndios florestais: módulo 2. Brasília, DF: ABEAS, 2002. 120 p.

SHOW, S. B.; CLARKE, B. Elements of forest fire control. Roma: FAO, 1953. p. 18-19. 